10. Барях А.Б., Андрейко С.С., Федосеев А.К. О механизме локализации очагов газодинамических явлений в почве сильвинитовых пластов // Вестн. ПНИПУ: Геология. Нефтегазовое и горное дело. - 2017. - T. 16, № 3.- C. 247-254. DOI: 10.15593/2224-9923/2017.3.5.

11. Андрейко С.С., Лукьянец Е.В., Литвиновская Н.А., Нестеров Е.А., Бобров Д.А., Поляков А.Л., Лутович Е.А. Параметры профилактической дегазации пород почвы горных выработок при слоевой отработке третьего калийного пласта на рудниках ОАО «Беларуськалий» // Вестн. ПНИПУ: Геология. Нефтегазовое и горное дело. - 2017. - Т. 16, № 3.- С. 280-290. DOI: 10.15593/2224-9923/2017.3.9.

12. Andreyko S.S., Lyalina T.A. Rockburst from floors // Soils and Rocks. - 2019. - V. 42, 1. - P. 77-82. DOI: 10.28927/SR.421077.

13. Андрейко С.С. Современное состояние проблемы газодинамических явлений на действующих и вводимых в эксплуатацию калийных рудниках // Горное эхо. - 2019. - № 2 (75). - С. 82-89. DOI: 10.7242/echo.2019.2.20.

14. Андрейко С.С., Иванов О.В., Нестеров Е.А. Исследование способов предотвращения внезапных отжимов призабойной части соляных пород // Горный журнал. - 2018. - № 6. - C.30-34. DOI: 10.17580/gzh.2018.06.06.

15. Андрейко С.С., Литвиновская Н.А., Сиренко Ю.Г., Чаянов А.Б. Предотвращение газодинамических явлений из почвы горных выработок при различных вариантах столбовой системы разработки на рудниках ОАО «Беларуськалий» // Горн. журн. - 2018. - № 8. - С. 29-33. DOI: 10.17580/gzh.2018.08.02.

16. Барбиков Д.В., Андрейко С.С., Иванов О.В., Бобров Д.А. Оценка газодинамических характеристик горных пород Краснослободского разлома // Горн. журн. - 2018. - № 8. - С. 38-42. DOI: 10.17580/gzh.2018.08.04.

17. Андрейко С.С., Литвиновская Н.А. Локальный прогноз зон, опасных по газодинамическим явлениям из почвы горных выработок пласта АБ на южной части шахтного поля БКПРУ -4 Верхнекамского месторождения калийных солей // Горный информационно-аналитический бюллетень (научнотехнический журнал). - 2013. - № 4. - С. 205-211.

18. Андрейко С.С., Иванов О.В., Нестеров Е.А., Головатый И.И., Береснев С.П. Исследование газоносности соляных пород третьего калийного пласта на шахтном поле Краснослободского рудника // Горн. журн. - 2013. - № 6. - С. 69-73.

19. Тараканов В.А., Головатый И.И., Береснев С.П., Андрейко С.С., Иванов О.В. Исследование газоносности пород пласта третьего калийного горизонта Старобинского месторождения // Горн. журн. 2010. - № 8. - С.25-27.

20. Медведев И.И., Полянина Г.Д. Газовыделения на калийных рудниках. - М.: Недра, 1974. - 163 с.

21. Земсков А.Н., Кондрашев П.И., Травникова Л.Г. Природные газы калийных месторождений и меры борьбы с ними. - Пермь: Тип. Купца Тарасова, 2008. - 412 с.: ил., табл.

22. Лейбензон Л.С. Движение природных жидкостей и газов в пористой среде // Собрание трудов. - М., 1951-1955. -4 т.

УДК 622.253

DOI:10.7242/echo.2020.2.19

\title{
АНАЛИЗ ЭФФЕКТИВНОСТИ ПРИМЕНЕНИЯ ГАЗОВЫХ КАЛОРИФЕРОВ ПРЯМОГО НАГРЕВА В УСЛОВИЯХ ШАХТ И РУДНИКОВ
}

\author{
Д.А. Бородавкин, А.В. Зайцев \\ Горный институт УрО РАН, г. Пермь
}

\begin{abstract}
Аннотация: В данной работе рассматриваются существующие способы нагрева воздуха в холодный период года и производится их сравнение. Приводится анализ изменения компонентного состава нагреваемого воздуха на примере действующей системы прямого нагрева воздуха. Выявляется дополнительный критерий, оказывающий влияние на экономическое обоснование таких систем.

Ключевые слова: система воздухоподготовки, газовая горелка, прямой нагрев воздуха, энергоэффективность, предельно допустимая концентрация.

Свежий воздух, поступающий в подземные горные выработки в холодный период, следует нагревать до температуры не менее $+2{ }^{\circ} \mathrm{C}$ для обогрева воздухоподающего ствола. Для этого шахты и рудники оборудуются системами воздухоподготовки. На сегодняшний день в качестве воздухонагревателей наибольшую популярность получили
\end{abstract}


водяные калориферы. Принцип работы систем, использующих калориферы, заключается в следующем: воду нагревают в котельных, после чего по системе трубопроводов подают в рекуперативные теплообменники (калориферы), где происходит нагрев воздуха посредством теплообмена с горячей водой через металлическую трубку. Несмотря на высокую надежность, хорошую ремонтопригодность и возможность эффективного центрального и местного регулирования теплопроизводительности, такие системы обладают рядом недостатков:

- высокая металлоемкость (применение большого числа металлических калориферов, необходимость прокладки теплотрасс от котельных до систем воздухоподготовки);

- зависимость отпуска тепла от тепловой сети и центральной котельной;

- возможность размораживания калориферов из-за внешних причин, таких как гидравлический удар, порыв теплотрассы и т.д.;

- $\quad$ несовпадение графика отпуска тепла промплощадки с требуемым графиком системы воздухоподготовки;

- сравнительно невысокий КПД.

Весьма перспективными представляются системы с газовыми теплогенераторами. Такие системы обладают следующими преимуществами:

- высокая надежность;

- отсутствие опасности обмерзания;

- плавное регулирование тепловой мощности;

- низкая металлоемкость (системы расположены в непосредственной близости к стволам, не требуется прокладка многокилометровых тепловых сетей);

- высокий КПД;

- наиболее низкие эксплуатационные затраты в сравнении с водяными и электрическими калориферами $[1,2,5]$.

Помимо рассмотренных вариантов на предприятиях применяются электрические калориферы, однако такие установки не нашли широкого применения ввиду высоких эксплуатационных затрат $[3,6]$. На рис. 1 представлено сравнение стоимости 1 Гкал при выработке газовыми, водяными и электрическими установками [5].

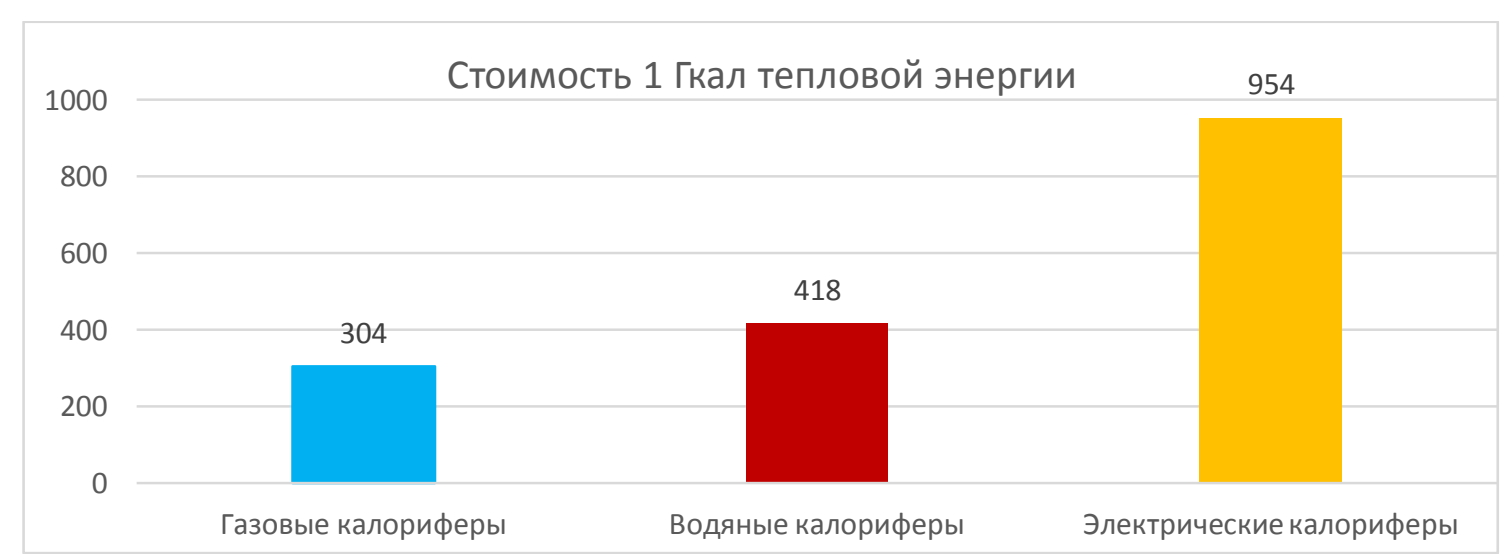

Рис. 1. Диаграмма стоимости 1 Гкал при выработке ее различными калориферными установками

Согласно представленным данным на рис. 1, стоимость 1 Гкал тепловой энергии при выработке электрическими калориферами в 3,1 раза выше, чем при выработке газовыми калориферами и в 2,3 раза выше, чем при выработке водяными калориферами.

По способу нагрева выделяют два типа газовых воздухонагревателей. В первом случае атмосферный воздух нагревается за счет его смешивания с продуктами сгорания при открытом сжигании газа в воздушном потоке (калориферы прямого нагрева, ПНВ). 
Во втором нагрев осуществляется в газо-воздушных рекуператорах через стальную поверхность, теплоносителем при этом являются продукты сгорания газа, которые выбрасываются за пределы воздухозабора шахты [7].

Калориферы прямого нагрева представляют особый интерес, поскольку обладают КПД близким к $100 \%$ за счет того, что вся теплота, получаемая в результате химической реакции, используется для нагрева воздуха. Несмотря на преимущества, данный метод нагрева обладает особенностью, которую следует учитывать при проектировании и обосновании принятия решения по выбору данного способа нагрева:

- поступление продуктов сгорания в шахтную атмосферу $\left(\mathrm{CO}_{2}, \mathrm{NO}_{2}\right.$ и оксиды азота в пересчете на $\mathrm{NO}_{2}$ );

- $\quad$ опасность превышения ПДК по выделяемым в результате горения газам, в случае нарушения горения величина которых может превысить ПДК в руднике [8].

Сжигание метана происходит согласно реакции, представленной ниже

$$
\mathrm{CH}_{4}[\text { газ }]+2 \mathrm{O}_{2}[\text { газ }]=\mathrm{CO}_{2}[\text { газ }]+2 \mathrm{H}_{2} O[\text { пар }]+Q_{\mathrm{H}}
$$

Продуктами полного сгорания газов выступают водяные пары и диоксид углерода.

1 молекула метана при взаимодействии с 2 молекулами кислорода образует 1 молекулу двуокиси углерода и 2 молекулы воды.

Рассчитаем количество вещества метана в $1 \mathrm{~m}^{3}$ согласно закону Авогадро:

$$
\mathrm{n}\left(\mathrm{CH}_{4}\right)=1000 \text { л } / 22,4 \text { л } / \text { моль }=44,6 \text { моль }
$$

Рассчитаем объем выделившейся в ходе реакции воды:

$$
\begin{gathered}
\mathrm{m}\left(\mathrm{H}_{2} \mathrm{O}\right)=\mathrm{n}\left(\mathrm{H}_{2} \mathrm{O}\right) \cdot M=2 \cdot 44,6 \text { моль } \cdot 18 \text { г/моль }=1607 \text { г } \\
V\left(\mathrm{H}_{2} \mathrm{O}\right)=\frac{\mathrm{m}\left(\mathrm{H}_{2} \mathrm{O}\right)}{\rho\left(\mathrm{H}_{2} \mathrm{O}\right)}=0,0016 \mathrm{м}^{3}
\end{gathered}
$$

Рассчитаем объем выделившегося в ходе реакции углекислого газа:

$$
\begin{gathered}
\mathrm{m}\left(\mathrm{CO}_{2}\right)=\mathrm{n}\left(\mathrm{CO}_{2}\right) \cdot M=44,6 \text { моль } \cdot 44 \text { г моль }=1962 г \\
V\left(\mathrm{CO}_{2}\right)=\frac{\mathrm{m}\left(\mathrm{CO}_{2}\right)}{\rho\left(\mathrm{CO}_{2}\right)}=0,9925 \mathrm{~m}^{3}
\end{gathered}
$$

Таким образом, при сжигании $1 \mathrm{~m}^{3}$ метана в результате реакции сжигания выделяется $0,0016 \mathrm{~m}^{3}$ водяных паров и $0,9925 \mathrm{~m}^{3}$ углекислого газа.

Помимо этого, в зависимости от температуры горения, времени пребывания продуктов сгорания в зоне генерации оксидов азота и других факторов в ходе реакции могут выделяться оксиды азота. Термические из молекулярного азота воздуха, топливные из азота, содержащегося в топливе, так называемые быстрые при реакции молекулярного азота воздуха с углеводородными радикалами.

Согласно ФНиП «Правила безопасности при ведении горных работ и переработке полезных ископаемых» [9], воздух в действующих подземных выработках не должен содержать ядовитых газов (паров) больше предельно допустимых концентраций, представленных в табл. 1.

Таблица 1

Предельные концентрации выделяемых в результате химической реакции продуктов горения

\begin{tabular}{|c|c|c|c|}
\hline \multirow{2}{*}{$\begin{array}{c}\text { Наименование } \\
\text { вещества }\end{array}$} & $\begin{array}{c}\text { Химическая } \\
\text { формула }\end{array}$ & \multicolumn{2}{|c|}{$\begin{array}{c}\text { Предельно допустимая } \\
\text { концентрация }\end{array}$} \\
\cline { 3 - 4 } & $\mathrm{CO}$ & $\mathrm{Mг} / \mathrm{M}^{3}$ & \% по объему \\
\hline Углекислый газ & $\mathrm{NO}_{2}$ & 20 & 0,0017 \\
\hline Азот & & 5 & 0,00026 \\
\hline
\end{tabular}


Для обеспечения устойчивого горения системы прямого нагрева воздуха, согласно [10], оборудуются автоматикой безопасности, которая должна обеспечивать прекращение подачи газа на горелки воздухонагревателя при:

- погасании контролируемого пламени горелки;

- повышении давления газа перед горелками выше допустимого значения;

- понижении давления газа перед горелками ниже допустимого значения;

- остановке вентилятора, подающего воздух для смешивания;

- понижении давления воздуха, идущего на горение, перед горелками;

- принудительной подаче воздуха ниже допустимого значения;

- прекращении подачи энергии.

Помимо этого, для обеспечения требуемого состава воздуха системы прямого нагрева воздуха оборудуются датчиками контроля состава воздуха, подаваемого в шахту [11].

Проведенное автором работы обследование системы прямого нагрева воздуха на шахте «Северопесчанская» ОАО «Богословского рудоуправления» ООО «УГМКХолдинг» показало, что применение средств контроля горения позволяет избежать превышения ПДК продуктов сгорания в подаваемом в шахту воздухе. Ниже представлены основные результаты обследования.

Система прямого нагрева воздуха (ПНВ) состоит из четырех воздухонагревателей газовых смесительных РГ 1000 КМТ, двух подводящих газопроводов с узлами автоматического отключения и контроля плотности, системы электрообогрева оборудования, автоматизированной системы управления. Каждый воздухонагреватель имеет максимальную мощность 3,07 МВт и производительность 55 м 3 с.

Для оценки влияния газогорелочных устройств на состав воздушной среды произведен отбор газовых проб в трех основных объемах:

- наружный воздух (атмосфера);

— после горелочных устройств;

— в калориферном канале.

По результатам отбора газовых проб получены величины концентраций $\mathrm{CH}_{4}, \mathrm{CO}_{2}$, $\mathrm{O}_{2}$ и $\mathrm{N}_{2}$, представленные в табл. 2.

Таблица 2

Результаты отбора газовых проб в системе ПНВ

\begin{tabular}{|c|c|c|c|c|c|}
\hline \multirow{2}{*}{ Место отбора проб } & \multirow{2}{*}{ № замера } & \multicolumn{4}{|c|}{ Концентрация газа } \\
\cline { 3 - 6 } & & $\mathbf{C H}_{\mathbf{4}}$ & $\mathbf{C O}_{\mathbf{2}}$ & $\mathbf{O}_{\mathbf{2}}$ & $\mathbf{N}_{\mathbf{2}}$ \\
\hline \multirow{3}{*}{$\begin{array}{c}\text { Забор наружного воздуха в } \\
\text { калориферную }\end{array}$} & I & 0.00022 & 0.04848 & 20.27458 & 79.6767 \\
\cline { 2 - 6 } & II & 0.00019 & 0.04656 & 20.27210 & 79,6182 \\
\cline { 2 - 6 } & среднее & $\mathbf{0 . 0 0 0 2 1}$ & $\mathbf{0 . 0 4 7 5 2}$ & $\mathbf{2 0 . 3 7 3 3 4}$ & $\mathbf{7 9 . 6 7 8 9}$ \\
\hline \multirow{3}{*}{\begin{tabular}{c} 
После газовой горелки \\
\cline { 2 - 6 }
\end{tabular}} & I & 0.00019 & 1.16736 & 18.06202 & 80.7704 \\
\cline { 2 - 6 } & II & 0.00023 & 1.38153 & 17.47704 & 81.1412 \\
\hline \multirow{2}{*}{ Калориферный канал } & Іреднее & $\mathbf{0 . 0 0 0 2 1}$ & $\mathbf{1 . 2 7 4 4 4}$ & $\mathbf{1 7 . 7 6 9 5 3}$ & $\mathbf{8 0 . 9 5 5 8}$ \\
\cline { 2 - 6 } & II & 0.00021 & 0.05410 & 20.30567 & 79.6400 \\
\cline { 2 - 6 } & среднее & $\mathbf{0 . 0 0 0 2 3}$ & $\mathbf{0 . 0 5 4 2 1}$ & $\mathbf{2 0 . 3 3 0 9 7}$ & $\mathbf{7 9 . 5 6 4 6}$ \\
\hline
\end{tabular}


Согласно обработанным замерам, в результате сжигания природного газа концентрация $\mathrm{CO}_{2}$ увеличивается с $0,05 \%$ до 1,27\%, концентрация $\mathrm{O}_{2}$ снижается с 20,4\% до $17,8 \%$. После чего происходит разбавление продуктов горения атмосферным воздухом, в результате которого концентрация $\mathrm{CO}_{2}$ составляет 0,05\% (ПДК составляет 0,5\%), концентрация $\mathrm{O}_{2}$ составляет $20,3 \%$ (содержание кислорода в воздухе выработок, в которых находятся или могут находиться люди, должно составлять не менее 20\%).

Существующая система контроля количества газов в камере смешения позволяет избежать превышения ПДК в подаваемом в рудник воздухе. Тем не менее продукты сгорания оказывают влияние на компонентный состав воздуха. Снижение доли кислорода в воздухе требует увеличения объема воздуха, используемого при проветривании рабочих зон, что способствует увеличению затрат на вентиляцию и, как следствие, должно учитываться при обосновании выбора данного способа нагрева.

\section{Выводы}

1. Разработка систем прямого нагрева воздуха, основанных на использовании газовых калориферов смесительного типа, позволяет существенно снизить эксплуатационные затраты в сравнении с водяными и электрическими калориферами, обеспечивая при этом высокую надежность и эффективность.

2. Применяемые системы должны соответствовать требованиям нормативных документов касательно контроля процесса сжигания газа, а также контроля за компонентным составом воздуха, подаваемого в шахту.

3. Необходимо учитывать изменение компонентного состава воздуха при расчете требуемого количества воздуха согласно действующим на рудниках методикам. Эксплуатационные затраты, связанные с увеличением нагрузки на вентиляцию, должны учитываться при экономическом обосновании систем прямого нагрева воздуха.

Работа выполнена при поддержке Программы ФНИ, проект № 0422-2019-0145-С-01.

\section{БИБЛИОГРАФИЧЕСКИЙ СПИСОК}

1. Левин Л.Ю. Моделирование и расчет систем обогрева шахтных воздухоподающих стволов // Горный информационно-аналитический бюллетень. - 2008. - № 10. - С. 49-54.

2. Казаков Б.П, Шалимов А.В. Разработка энергосберегающей системы автоматического управления проветриванием рудников // Изв. вузов. Горн. журн. - 2012. - № 3. - С. 57-63.

3. Левин Л.Ю., Казаков Б.П. Использование газовых теплогенераторов в системах обогрева воздухоподающих стволов калийных рудников // Горн. информ.-аналит. бюл. - 2008. - № 10. - С. 55-59.

4. Левин Л.Ю. Проектирование вспомогательных систем обогрева вентиляционных стволов // Научные исследования и инновации. - 2009. - Т. 3, № 4. - С. 42-44.

5. Левин Л.Ю. Теоретические и технологические основы ресурсосберегающих систем воздухоподготовки рудников: дис. ... д.т.н.: 25.00.20: защищена 29.04.10 / Левин Лев Юрьевич. - Пермь, 2010. - 275 с.

6. Николаев А.В., Алыменко Н.И., Файнбург Г.З., Седунин А.М., Николаев В.А. Расчет теплопроизводительности шахтной калориферной установки, расположенной в калориферном канале, и затрачиваемой на ее работу электроэнергии // Изв. вузов. Горн. журн. - 2014. - № 4. - С. 105-112.

7. Рязанов В.И., Щелоков А.В. Сравнительная характеристика газовых воздухонагревателей смесительного типа // Молодежь и XXI век - 2018: Материалы VIII Междунар. молодежной науч. конф. - 2018. - Т. 5. - С. 231-234.

8. Алабьев В.Р. Совершенствование технических решений по обеспечению безопасности обогрева воздухоподающих стволов угольных шахт газовыми воздухонагрвеателями // Вестник Забайкальского Гос. Ун-та. - 2016. - Т. 22, № 10. - С. 4-13. DOI: 10.21209/2227-9245-2016-22-10-4-13.

9. Федеральные нормы и правила в области промышленной безопасности «Правила безопасности при ведении горных работ и переработке твердых полезных ископаемых». Вып. 78: утв. 11.12.2013, № 32935. - М.: ЗАО НТЦ ПБ, 2016. - 276 с. - (Документы межотраслевого применения по вопросам промышленной безопасности и охраны недр: сер. 03).

10. ГОСТ 31849-2012 Оборудование промышленное газоиспользующее. Воздухонагреватели смесительные. Общие технические требования: дата введения 2014-01-01. - Текст электронный // Консорциум КОДЕКС. Электронный фонд правовой и нормативно-технической документации: офиц. сайт. URL: http://docs.cntd.ru/document/1200101752 (Дата обращения 10.06.2020)

11. Мысляков А.Л., Плотников В.В., Балдин Д.А. Применение систем прямого нагрева воздуха для вентиляции шахт // Безопасность труда в промышленности. - 2003. - № 11. - С. 11-12. 